\title{
Stability of the Anterior Maxillary Segment and Teeth after Segmental Le Fort I Osteotomy and Postoperative Skeletal Elastic Fixation With or Without Occlusal Splint
}

\author{
Tue Lindberg Blæhr ${ }^{1}$, Thomas Jensen ${ }^{1}$, Karen Margrethe Due ${ }^{2}$, Bjarne Neumann-Jensen ${ }^{1}$ \\ 'Department of Oral and Maxillofacial Surgery, Aalborg University Hospital, Aalborg, Denmark. \\ ${ }^{2}$ Center for Cardiovascular Research, Aalborg University Hospital, Aalborg, Denmark.
}

\author{
Corresponding Author: \\ Tue Lindberg Blæhr \\ Department of Oral and Maxillofacial Surgery \\ Aalborg University Hospital \\ Hobrovej 18-22, 9000 Aalborg \\ Denmark \\ Phone: + 4597662795 \\ E-mail: t.blaehr@rn.dk
}

\begin{abstract}
Objectives: To assess the short term dental and skeletal stability of the anterior maxillary segment after segmental Le Fort I osteotomy with postoperative skeletal elastic fixation with or without occlusal splint.

Material and Methods: 29 consecutive patients underwent segmental Le Fort I osteotomy and elastic skeletal fixation was applied. Patients were divided into two groups according to whether a fixed occlusal splint was used for six weeks (group A) or dismounted perioperatively (group B). Changes in landmarks and reference planes between the two timepoints were estimated on lateral cephalometric radiographs.

Results: Group A: The upper incisor had a mean intrusion of $-0.56 \mathrm{~mm}$ (SD 0.77; range -2.04 to $1.08 \mathrm{~mm}$ ) and a mean posterior movement of $-0.93 \mathrm{~mm}$ (SD 1.03; range -2.52 to $0.96 \mathrm{~mm}$ ). The mean change in the axial inclination of the upper incisor was $-0.33^{\circ}$ (SD 2.56; range $-6^{\circ}$ to $\left.4^{\circ}\right)\left(95 \% \mathrm{CI}:-1.75\right.$ to $\left.1.08^{\circ}\right)$. Group B: The upper incisor had a mean intrusion of $-0.13 \mathrm{~mm}$ (SD 1.36; range -1.92 to $3.6 \mathrm{~mm}$ ) and a mean anterior movement of $0.11 \mathrm{~mm}$ (SD 1.78; range -2.88 to $3.84 \mathrm{~mm}$ ). The mean change in the axial inclination of the upper incisor was $-0.07^{\circ}$ (SD 3.05 ; range $-5^{\circ}$ to $5^{\circ}$ ) $\left(95 \% \mathrm{CI}\right.$ : -1.83 to $1.69^{\circ}$ ). There was no statistically significant difference in stability between the two groups at the P value 0.05 .

Conclusions: The skeletal anterior fixation with postoperative elastics for eight weeks may not compromise the early postoperative dental and skeletal stability of the anterior segment in segmental Le Fort I osteotomy.
\end{abstract}

Keywords: maxillofacial orthognatic surgery; LeFort osteotomy; open bite; skeletal fixation.

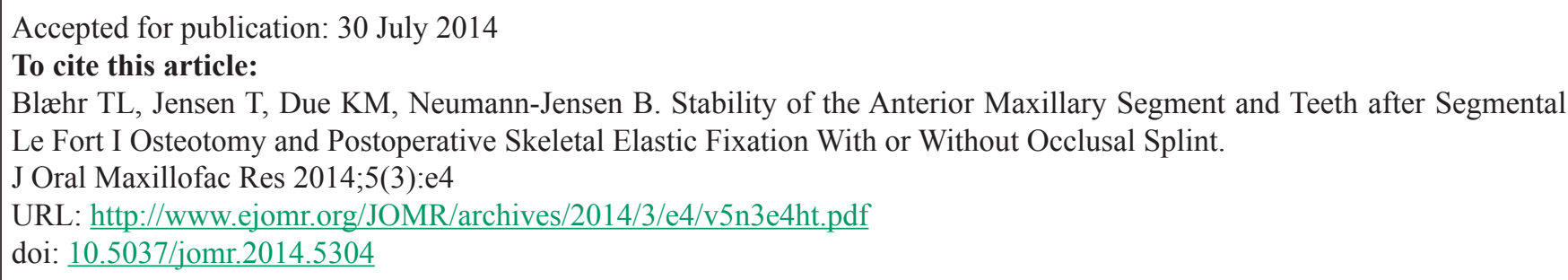




\section{INTRODUCTION}

Treatment of anterior open bite with segmental Le Fort I osteotomy is regarded as a surgical procedure with less predictable result and increased risk of relapse [1]. Several dental and skeletal factors are thought to contribute to vertical relapse involving postoperative retroclination of the incisors, tongue size and posture, respiratory problems or condylar resorption [2-4].

In order to prevent relapse, a stable postoperative occlusion and sufficient internal fixation is important [5]. Different approaches and techniques have been advocated to prevent skeletal relapse after surgical correction of maxillofacial deformities []․ Ellis et al. [7] found the use of skeletal wire fixation in the form of circummandibular wires attached to piriform aperture or anterior nasal spine advantageous in preventing horizontal skeletal relapse. In addition, this technique may also add to the early postsurgical stability in a behaviour-modifying manner e.g. in acting against an established parafunctional habit of tongue thrusting and/or to guide the patient into the planned occlusion. However, skeletal wires with elastics from the anterior nasal spine to the mental symphysis could induce pressure on the anterior maxillary segment in the early postoperatively period, which may cause orthodontic forces on the anterior teeth and compromise the dental and skeletal stability. Maintenance of the occlusal splint in combination with rigid fixation of the anterior segment may reduce the risk of vertical and horizontal changes of the anterior teeth in the early postoperative period. Therefore, the objective of the present study was to assess the null-hypothesis that there was no statistically significant difference in the early postoperatively dental and skeletal stability of the anterior maxillary segment after segmental Le Fort I osteotomy and postoperative skeletal elastic fixation with or without a fixed occlusal splint.

\section{MATERIAL AND METHODS Patients}

From June 2008 to July 2012, 29 patients with anterior open bite or large Angle Class II deficiency underwent either segmental Le Fort I osteotomy alone, or in combination with bilateral sagittal split osteotomy (BSSO). The patients were divided into two groups according to whether a fixed occlusal splint was used for six weeks (group A) or dismounted immediately after surgery (group B). Group A consisted of 15 patients, 8 female and 7 male, with a mean age of 19.5 years (range $15-26$ years). In group A 14 patients had bimaxillary surgery and 1 patient had segmental Le Fort I osteotomy only. Group B consisted of 14 patients, 8 female and 6 male, with a mean age of 25.4 years (range $15-48$ years). In group B 12 patients had bimaxillary surgery and 2 patients had segmental Le Fort I osteotomy only (Table 1). All patients were determined to have ended their pubertal growth rate. Surgery was performed by 3 senior maxillofacial surgeons.

All patients were treated at the Department of Oral and Maxillofacial Surgery, Aalborg University Hospital, Aalborg, Denmark. Patients with craniofacial deformities or previous trauma to the facial skeleton were excluded. Due to the retrospective nature of this study it was granted an exemption in writing by the Aalborg University Hospital IRB.

\section{Procedure \\ Preoperatively}

Two weeks before surgery, the patients were seen by the operating surgeon. With dental casts, standard cephalometric lateral radiographs and a surgical planning programme (Dolphin Imaging \& Management Solutions, Patterson Technology, Chatsworth, CA, USA) the definitive treatment plan was determined and occlusal splints fabricated.

\section{Surgical technique}

Surgery was performed under general anaesthesia with nasotracheal intubation. The segmental Le Fort I osteotomies were performed as described by Bell [8] with vertical interdental osteotomies mesial to the canines connected to a U-shaped osteotomy in the palate. After mobilization of the segments the occlusal splint was ligated to the teeth in the maxilla with $0.4 \mathrm{~mm}$ wires. In all patients IMF was applied using $0.4 \mathrm{~mm}$ wires and elastics. After verifying the new position of the maxilla in all three dimensions, the maxilla was stabilized with L-shaped $1.7 \mathrm{~mm}$ titanium plates (Stryker Leibinger, Freiburg, Germany)

Table 1. Patients

\begin{tabular}{l|c|c}
\hline & Group A $^{\mathbf{a}}$ & Group B $^{\mathbf{b}}$ \\
\hline Number of patients & $15(8$ male, 7 female $)$ & $14(8$ male, 6 female $)$ \\
\hline Mean (range) age (years) & $19.5(15-26)$ & $25.4(15-48)$ \\
\hline
\end{tabular}

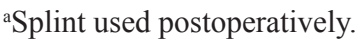

${ }^{\mathrm{b}}$ Splint dismounted immediately after surgery. 
at the zygomatic buttresses, the anterior aspect of the maxilla and at the pyriform aperture. A total of six plates were placed, three on each side. IMF was released and the occlusion in the splint was checked. An additional horizontal incision was made in the inferior alveololabial sulcus to expose the mental symphysis. All patients had skeletal wire fixation $0.6 \mathrm{~mm}$ secured at the anterior nasal spine and at the mental symphysis (Figure 1). The wires were bent to facilitate the application of skeletal elastic fixation postoperatively. The mucosa was sutured with resorbable 4-0 Vicryl. The peroperative fixed occlusal splint was either maintained for 6 weeks postoperatively (group A) or removed immediately after surgery (group B). The decision to maintain the splint or remove it was made by the operating surgeon.

\section{Postoperatively}

The skeletal elastic IMF was activated in both group $\mathrm{A}$ and $\mathrm{B}$ after the first week postoperatively with elastics connecting the wires from the symphysis to the anterior nasal spine. The skeletal elastic IMF was worn for 24 hours a day for the following eight weeks, only to be temporarily released during mealtimes and oral hygiene. The patients were seen after 1 week, 2 weeks, 3 weeks, 8 weeks, 6 months and 18 months at the Department of Oral and Maxillofacial Surgery, Aalborg University Hospital, Aalborg, Denmark. Concurrently all patients were followed-up by their respective orthodontist.

\section{Radiographic examination}

Digital lateral cephalometric radiographs (Orthoceph OC200D, Instrumentarium Dental, Tuusula, Finland) were used to analyze and measure the angulation and changes in the horizontal and vertical position of the anterior teeth. The radiographs were taken postoperatively at day 1 (T1) and after 8 weeks (T2). Reference planes and landmark identifications were performed by the principal investigator using CliniView 7.0.1 (Instrumentarium Dental, Tuusula, Finland) and the radiographs were corrected for magnification factor using the known distance of the ruler on the radiographs. Brightness and contrast adjustments were standardized using the above mentioned software programme. The upper central incisor tip (U1), Nasion (N), Sella (S) and the Sellanasion line (SNL) were identified. The landmarks and reference planes are shown in Figure 2. To evaluate the early postsurgical dental and skeletal stability of the segmented maxillary front, the cephalometric changes were measured relative to a coordinate system. The SNL represented the y-axis. A line perpendicular to this intersecting at the sella point represented the x-axis. U1 was identified and from this landmark a line was drawn through the apex of the upper incisor intersecting the SNL (U1SNL). The angular measurements of the axial inclination of the upper incisor relative to the $y$-axis were recorded in degrees and the linear measurements of U1 were recorded in millimetres [9].

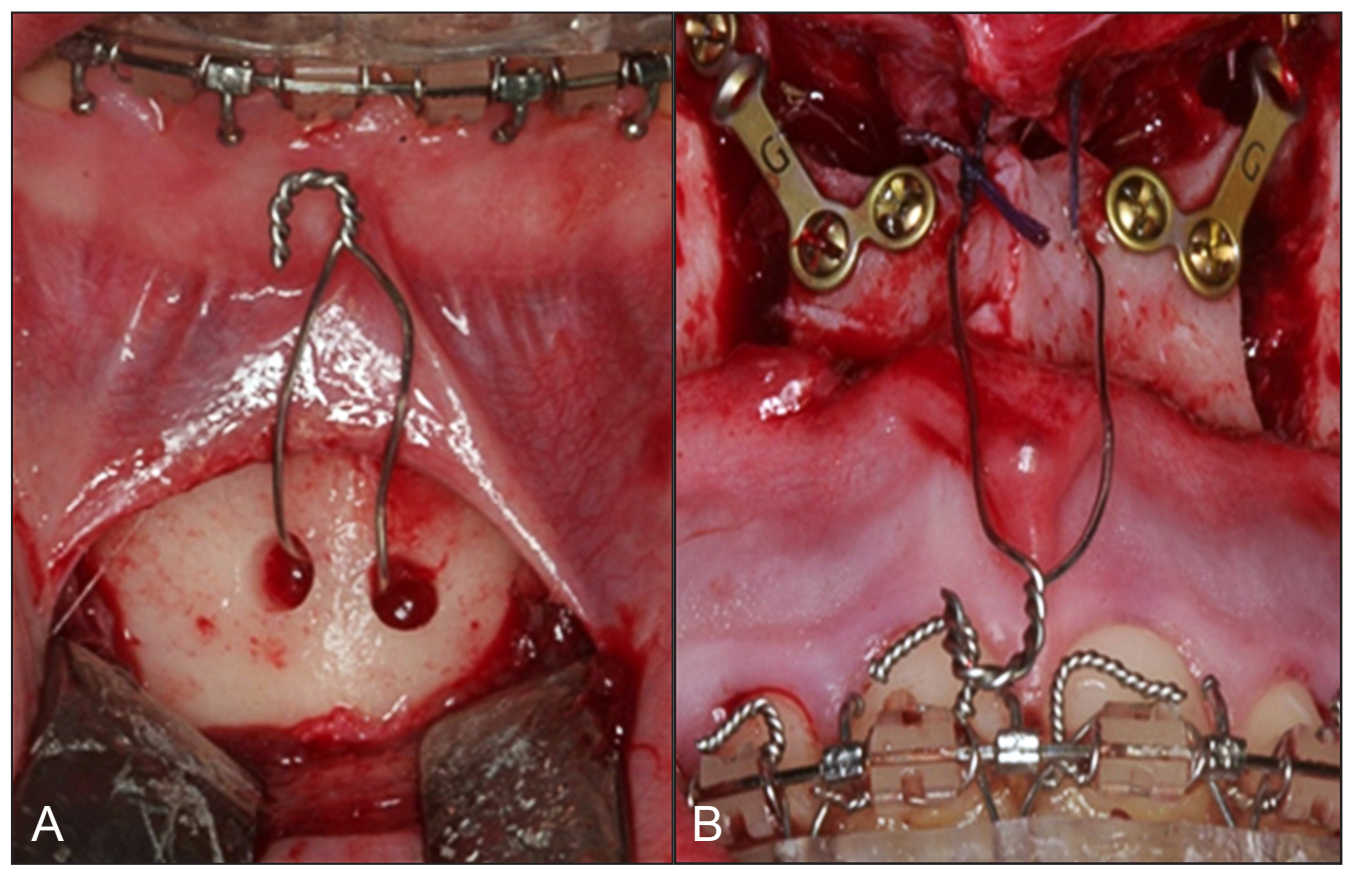

Figure 1. Intraoperative photographs, showing skeletal wires fixed at the symphysis (A) and at the anterior nasal spine (B). 


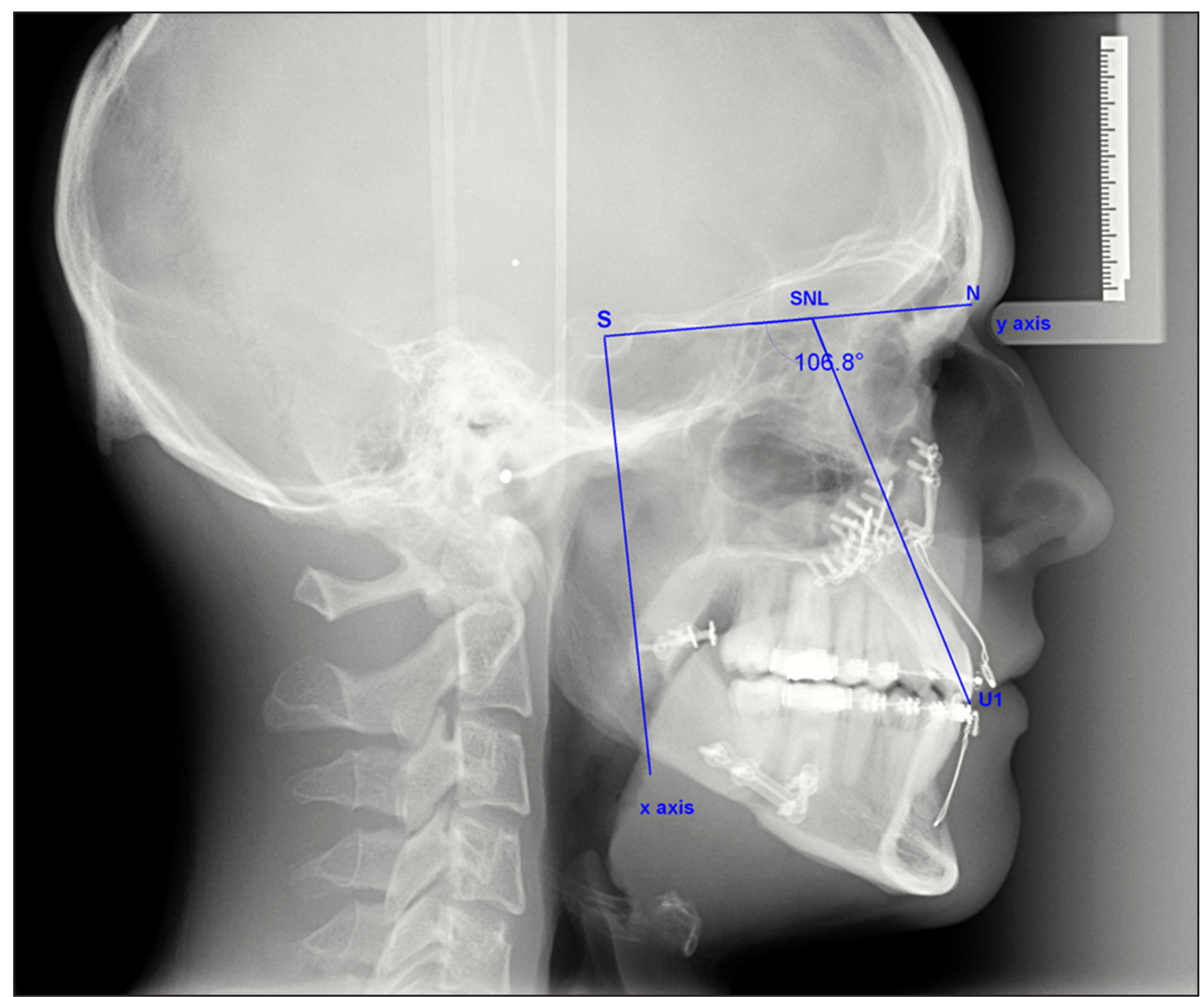

Figure 2. Lateral cephalometric radiograph showing landmarks and reference planes.

$\mathrm{U} 1=$ upper central incisor tip; $\mathrm{S}=$ sella; $\mathrm{N}=$ nasion; $\mathrm{SNL}=$ sella-nasion line.

\section{Statistical analysis}

Data management and analysis including calculation of descriptive statistics were carried out by means of the statistical software Stata 11.2, Datacorp. The primary descriptive variable was stability of the anterior maxillary segment with or without occlusal splint. The mean changes (M) and standard deviations (SD) of cephalometric variables between $\mathrm{T} 1$ and T2 were statistically compared between the groups. To describe the study population descriptive analyses with proportions and M (SD) were used. All analysis was performed using analysis of variance (ANOVA) both as crude and adjusted for sex and age. $P$ value $<0.05$ was considered as significant. An intraexaminer calibration was performed using 10 lateral cephalometric radiographs. The radiographs were traced and then retraced by the principal investigator two weeks after the initial tracings. To evaluate the tracing error a Bland-Altman plot for the two measurements was used.

\section{RESULTS}

Clinical evaluation demonstrated no obvious differences in the angulation or position of the anterior maxillary teeth between the two groups. Radiographic examination demonstrated that group A: U1 had a mean intrusive movement of $-0.56 \mathrm{~mm}$ (SD 0.77; range -2.04 to $1.08 \mathrm{~mm}$ ) and a mean posterior movement of $-0.93 \mathrm{~mm}$ (SD 1.03; range -2.52 to $0.96 \mathrm{~mm}$ ) from $\mathrm{T} 1$ to $\mathrm{T} 2$. The mean change in the axial inclination of the upper incisor (U1SNL) was a minor retroclination of $-0.33^{\circ}$ (SD 2.56; range $-6^{\circ}$ to $\left.4^{\circ}\right)\left(95 \%\right.$ CI: -1.75 to $\left.1.08^{\circ}\right)$.

Group B: U1 had a mean intrusive movement of -0.13 $\mathrm{mm}$ (SD 1.36; range -1.92 to $3.6 \mathrm{~mm}$ ) and a mean anterior movement of $0.11 \mathrm{~mm}$ (SD 1.78; range -2.88 to $3.84 \mathrm{~mm}$ ) from $\mathrm{T} 1$ to $\mathrm{T} 2$. The mean change in the axial inclination of the upper incisor (U1SNL) was a minor retroclination of $-0.07^{\circ}$ (SD 3.05; range $-5^{\circ}$ to $\left.5^{\circ}\right)\left(95 \%\right.$ CI: -1.83 to $\left.1.69^{\circ}\right)$.

There were no statistical significant differences at the P level 0.05 between group A and B for the linear changes in $\mathrm{X}$-coordinates $(\mathrm{P}=0.3)$, the linear changes 
in Y-coordinates $(\mathrm{P}=0.06)$, and the angular changes in axial inclination of the upper incisor $(\mathrm{P}=0.8)$ (Table 2).

A scatter diagram showed no relation between the differences of the repeated estimates against the corresponding means (Bland Altman 1986), demonstrating no systematic differences between the two measurements.

\section{DISCUSSION}

The early postoperative dental and skeletal stability of the anterior maxillary segment after segmental Le Fort I osteotomy with postoperative skeletal elastic fixation with or without occlusal splint was retrospectively assessed in 29 patients. Measurements on standard lateral cephalometric radiographs obtained on the first postoperative day and after eight weeks were compared revealing no statistical difference in stability between the two treatment modalities.

Stability of orthognathic surgery has been assessed in several studies $[\underline{1}, \underline{3}, \underline{5}, \underline{1}, \underline{10-17]}$. The focus has been on both postsurgical stability (changes within the first year after surgery) and post-treatment stability (changes beyond one year after surgery) [18]. Surgical treatment of anterior open-bite is prone to some relapse and no high-level controlled evidence for the therapeutic efficacy or stability exists [19]. A recent well-designed retrospective study by Maia et al. [20] evaluated the long-term stability of surgical-orthodontic open-bite correction. Their sample included 39 patients with an open-bite malocclusion with an initial mean age of 20.83 years which is comparative to the present study. Maia et al. [20] both evaluated skeletal and dento-alveolar changes with a mean post-treatment follow-up time of 8.22 years. They found a statistically significant open-bite relapse in their overall sample. Amongst other factors contributing to an open-bite relapse they mention the postsurgical labial tipping of the maxillary incisor. In the present study, both groups had a minor retroclination of the maxillary incisor at T2 after 8 weeks. Of the results from the study by Maia et al. [20] one would expect to see the same changes in angulation over time i.e. a proclination of the maxillary incisors.

The present study could not detect any statistically significant difference in the early postsurgical position of the anterior teeth and stability of the segmented maxillary front whether a fixed occlusal splint was used for six weeks postoperatively or dismounted immediately after surgery. Our findings must be regarded with some caution as there are some limitations due to the retrospective study design and the relative small number of patients. Although the sample consisted of consecutive patients, there is a potential for selection bias. The patients were not randomly assigned to the two treatment groups and the decision to maintain the occlusal splint or to discharge it peroperatively was a decision made by the operating surgeon. As no information regarding the background for the surgeon's decision is available in this retrospective study, one might suspect, that only patients with an optimal occlusion had the splint removed peroperatively. Moreover, the results of the present study is based on dental measurements on lateral cephalometric radiographs, and therefore mainly reveal changes in angulation and the horizontal and vertical position of the upper anterior teeth rather than skeletal instability of the anterior maxillary segment.

The study has not assessed the presurgical position of the anterior maxillary segment and teeth. Therefore, possible confounding factors related to this might influence the short term stability e.g. the magnitude of movements and presurgical orthodontics. The present study concurs with the fact that, when considering postsurgical and post-treatment stability, most of the changes occur in a few of the patients and mean changes and standard deviations, therefore, can be misleading [18]. In most of the patients in the present study only minor linear changes $(\leq 2 \mathrm{~mm})$ were noted. Only two patients exhibited linear changes of $3-4$ $\mathrm{mm}$ which is of clinical relevance. However, in these two cases, the occlusion was finally adjusted with orthodontic treatment.

To the best of our knowledge, no study has investigated the early postoperative dental and skeletal stability of the maxillary front after segmental Le Fort I osteotomy with postoperative skeletal elastic fixation with or without a fixed occlusal splint. 


\section{CONCLUSIONS}

Within the limitation of a retrospective study, the present study indicates that postoperative skeletal elastic fixation for eight weeks may not compromise the short term stability of the anterior segment and teeth in Le Fort I osteotomy. However, further randomized long-term studies involving a larger patient-group is needed before final conclusions can be made on this topic.

\section{ACKNOWLEDGMENTS AND DISCLOSURE STATEMENTS}

The authors report no conflicts of interest related to this study.

\section{REFERENCES}

1. Hoppenreijs TJ, Freihofer HP, Stoelinga PJ, Tuinzing DB, van’t Hof MA, van der Linden FP, Nottet SJ. Skeletal and dento-alveolar stability of le fort I intrusion osteotomies and bimaxillary osteotomies in anterior open bite deformities. A retrospective three-centre study. Int J Oral Maxillofac Surg. 1997 Jun;26(3):161-75. [Medline: 9180224] [doi: 10.1016/S0901-5027(97)80813-2]

2. Hoppenreijs TJ, Freihofer HP, Stoelinga PJ, Tuinzing DB, van't Hof MA. Condylar remodelling and resorption after le fort I and bimaxillary osteotomies in patients with anterior open bite. A clinical and radiological study. Int J Oral Maxillofac Surg. 1998 Apr;27(2):81-91. [Medline: 9565261] [doi: 10.1016/S0901-5027(98)80301-9]

3. Fischer K, von Konow L, Brattstrom V. Open bite: Stability after bimaxillary surgery--2-year treatment outcomes in 58 patients. Eur J Orthod. 2000 Dec;22(6):711-8. [Medline: 11212606] [doi: 10.1093/ejo/22.6.711]

4. Ellis E 3rd, McNamara JA Jr. Components of adult class III open-bite malocclusion. Am J Orthod. 1984 Oct;86(4):27790. [Medline: 6592976] [doi: 10.1016/0002-9416(84)90138-6]

5. Joss CU, Vassalli IM. Stability after bilateral sagittal split osteotomy advancement surgery with rigid internal fixation: A systematic review. J Oral Maxillofac Surg. 2009 Feb;67(2):301-13. [Medline: 19138603] [doi: 10.1016/j.joms.2008.06.060]

6. Steinhauser EW. Advancement of the mandible by sagittal ramus split and suprahyoid myotomy. J Oral Surg. 1973 Jul;31(7):516-21. [Medline: 4513460]

7. Ellis E 3rd, Gallo WJ. Relapse following mandibular advancement with dental plus skeletal maxillomandibular fixation. J Oral Maxillofac Surg. 1986 Jul;44(7):509-15. [Medline: 3459835] [doi: 10.1016/S0278-2391(86)80090-8]

8. Bell WH. Le forte I osteotomy for correction of maxillary deformities. J Oral Surg. 1975 Jun;33(6):412-26. [Medline: 1055202]

9. Rustemeyer J, Martin A. Assessment of Soft Tissue Changes by Cephalometric and Two-Dimensional Photogrammetry in Bilateral Sagittal Split Ramus Osteotomy Cases. J Oral Maxillofac Res. 2011 Oct 1;2(3):e2. [URL: http://www.ejomr.org/JOMR/archives/2011/3/e2/v2n3e2ht.htm] [Medline: 24421994] [PMC free article: $\underline{3886076}$ ] [doi: 10.5037/jomr.2011.2302]

10. Ahmed MM. Long-term stability of anterior segmental maxillary osteotomy. Int J Adult Orthodon Orthognath Surg. 1999;14(4):297-303. [Medline: 10895645]

11. Arpornmaeklong P, Heggie AA, Shand JM. A comparison of the stability of single-piece and segmental le fort I maxillary advancements. J Craniofac Surg. 2003 Jan;14(1):3-9. [Medline: 12947928] [doi: 10.1097/00001665-200301000-00002]

12. Epker BN, Wessberg GA. Mechanisms of early skeletal release following surgical advancement of the mandible. Br J Oral Surg. 1982 Sep;20(3):175-82. [Medline: 6958313] [doi: 10.1016/S0007-117X(82)80035-8]

13. Hughes R. Relapse following bilateral sagittal split osteotomy with rigid internal fixation. Evid Based Dent. 2009;10(3): 81-2. [Medline: 19820743] [doi: 10.1038/sj.ebd.6400671]

14. Maia FA, Janson G, Barros SE, Maia NG, Chiqueto K, Nakamura AY. Long-term stability of surgical-orthodontic open-bite correction. Am J Orthod Dentofacial Orthop. 2010 Sep;138(3):254.e1,254.e10; discussion 254-6. [Medline: 20816288]

15. Solano-Hernandez B, Antonarakis GS, Scolozzi P, Kiliaridis S. Combined orthodontic and orthognathic surgical treatment for the correction of skeletal anterior open-bite malocclusion: A systematic review on vertical stability. J Oral Maxillofac Surg. 2013 Jan;71(1):98-109. [Medline: 22695022] [doi: 10.1016/j.joms.2012.03.016]

16. Stansbury CD, Evans CA, Miloro M, BeGole EA, Morris DE. Stability of open bite correction with sagittal split osteotomy and closing rotation of the mandible. J Oral Maxillofac Surg. 2010 Jan;68(1):149-59. [Medline: 20066170] [doi: $10.1016 /$ j.joms.2009.07.105]

17. Swinnen K, Politis C, Willems G, De Bruyne I, Fieuws S, Heidbuchel K, van Erum R, Verdonck A, Carels C. Skeletal and dento-alveolar stability after surgical-orthodontic treatment of anterior open bite: A retrospective study. Eur J Orthod. 2001 Oct;23(5):547-57. [Medline: 11668874] [doi: 10.1093/ejo/23.5.547]

18. Proffit WR, Turvey TA, Phillips C. The hierarchy of stability and predictability in orthognathic surgery with rigid fixation: An update and extension. Head Face Med. 2007 Apr 30;3:21. [Medline: 17470277] [PMC free article: 1876453] [doi: 10.1186/1746-160X-3-21] 
19. Greenlee GM, Huang GJ, Chen SS, Chen J, Koepsell T, Hujoel P. Stability of treatment for anterior open-bite malocclusion: A meta-analysis. Am J Orthod Dentofacial Orthop. 2011 Feb;139(2):154-69. [Medline: 21300243] [doi: 10.1016/j.ajodo.2010.10.019]

20. Maia FA, Janson G, Barros SE, Maia NG, Chiqueto K, Nakamura AY. Long-term stability of surgical-orthodontic openbite correction. Am J Orthod Dentofacial Orthop. 2010 Sep;138(3):254.e1-254.e10. [Medline: 20816288]

\section{To cite this article:}

Blæhr TL, Jensen T, Due KM, Neumann-Jensen B. Stability of the Anterior Maxillary Segment and Teeth after Segmental Le Fort I Osteotomy and Postoperative Skeletal Elastic Fixation With or Without Occlusal Splint.

J Oral Maxillofac Res 2014;5(3):e4

URL: http://www.ejomr.org/JOMR/archives/2014/3/e4/v5n3e4ht.pdf

doi: $10.5037 /$ jomr.2014.5304

Copyright (C) Blæhr TL, Jensen T, Due KM, Neumann-Jensen B. Published in the JOURNAL OF ORAL \& MAXILLOFACIAL RESEARCH (http://www.ejomr.org), 1 October 2014.

This is an open-access article, first published in the JOURNAL OF ORAL \& MAXILLOFACIAL RESEARCH, distributed under the terms of the Creative Commons Attribution-Noncommercial-No Derivative Works 3.0 Unported License, which permits unrestricted non-commercial use, distribution, and reproduction in any medium, provided the original work and is properly cited. The copyright, license information and link to the original publication on (http://www.ejomr.org) must be included. 